\title{
DÜBLIN
}

Technological University Dublin ARROW@TU Dublin

2008-01-01

\section{Philosophy Matters in Engineering Studies}

\author{
William Grimson \\ Technological University Dublin, william.grimson@tudublin.ie \\ Mike Murphy \\ Technological University Dublin, mike.murphy@tudublin.ie \\ Steen Hyldgaard Christensen \\ University of Aarhus
}

See next page for additional authors

Follow this and additional works at: https://arrow.tudublin.ie/engineduccon

Part of the Other Engineering Commons

\section{Recommended Citation}

Grimson, W., Murphy, M., Christensen, S., Erno-Kjolhede, E.: Philosophy Matters in Engineering Studies.

The 38th. ASEE/IEEE Frontiers in Education Conference, Saratoga Springs, New York, USA. October 22-25, 2008.

This Conference Paper is brought to you for free and open access by the Engineering: Education and Innovation at ARROW@TU Dublin. It has been accepted for inclusion in Conference papers by an authorized administrator of ARROW@TU Dublin. For more information, please contact arrow.admin@tudublin.ie, aisling.coyne@tudublin.ie,gerard.connolly@tudublin.ie.

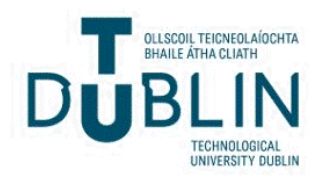




\section{Authors}

William Grimson, Mike Murphy, Steen Hyldgaard Christensen, and Erik Erno-Kjolhede

This conference paper is available at ARROW@TU Dublin: https://arrow.tudublin.ie/engineduccon/11 


\title{
Philosophy Matters in Engineering Studies
}

\author{
William Grimson, Mike Murphy, Steen Hyldgaard Christensen and Erik Ernø-Kjølhede \\ william.grimson@dit.ie,mike.murphy@dit.ie, steenhc@hih.au.dk, erik@hih.au.dk
}

\begin{abstract}
This article explores the rationale for including in an integrated five-years Masters Engineering programme liberal arts subjects, in particular Philosophy and the History of Science and Technology. We argue that the tools of philosophy should be used to provide additional insight into how engineering was and is 'performed'. We first review the challenge, next we present some results of an empirical case study carried out at AU-IBT in Denmark. The purpose of the case study was to examine a sample of engineering teachers' attitudes towards the relevance and scope of liberal arts subjects for engineering students. Finally we conclude with a proposal for the inclusion of Philosophy and History of Engineering, Science and Technology in an engineering programme and how this might be done.
\end{abstract}

Index Terms - Philosophy of science courses/liberal studies, Engineering epistemology; Philosophy of technology, Ethics, History of engineering, Engineering roles and identity.

\section{INTRODUCTION}

Some authors have predicted that if engineers do not accept hybrid engineering degree programmes they will be constrained to purely technical work activities. Consequently the graduating engineer would not be ideally suited to meet the requirements of the future labour market, which requires a degree of convergence between technological and non-technological skills. Educationalists on both sides of the Atlantic are thus pondering what changes, if any, are required to improve engineering education and to ensure that the engineers of the future can provide necessary leadership.

In his Presidential Address (Engineers Ireland) Who will be tomorrow's leader? The engineering profession's $21^{\text {st }}$ century challenge, Jack Golden noted that Plato believed that the foundation of leadership was expert knowledge, accompanied by such factors as courage, self-discipline and a philosophical mind [1]. It has been stated that the engineer is a 'composite' person in that it is not only science and 978-1-4244-1970-8/08/\$25.00 @2008 IEEE technology that is of concern: ethics, law, the impact on

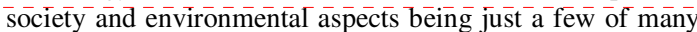
legitimate concerns that impact on how an engineer functions. Also, within industry, companies have identified the desired attributes that they seek in an engineer. All these revised skills and attributes leads one to the conclusion that the modern world requires a more rounded engineer, with the rounding provided by selected liberal arts studies. The above mentioned concerns represent a challenge for those responsible for the education and early development of tomorrow's engineer. Within the largest Engineering Faculty in Ireland, Dublin Institute of Technology, DIT, and in Denmark at the Aarhus University Institute of Business and Technology, AU-IBT, dialogue is ongoing amongst senior staff, first to explore the potential benefits of including some elements of liberal studies in the curriculum, and second, to consider how best this additional material would be presented. At face value it may seem as though the incorporation of liberal studies in engineering is meant to serve a merely instrumental agenda of promoting engineers for future leadership. But the scope is broader. We examine if engineering faculty members tend to see liberal studies as a) an unwelcome idea that will increase the pressure on curricula and defocus engineering programmes from their 'true purpose' or b) a positive innovation that may help decrease curricular pressure and educate more qualified and free-thinking engineering graduates.

\section{NATURE OF THE CHALLENGE}

Braslavsky notes that with the increasing pace of globalization the world is experiencing a remarkable culture process where 'the present culture change ... comes from the convergence of a number of transformations in practically all human activities which gives the totality greater breadth and depth than the simple sum of each one. In this totality, people ... become aware of the place of knowledge and education in societies, of the opportunities they open up, and of the risks involved in how they are currently distributed' [2].

Braslavsky lists six educational demands associated with the converging trends for change:

i) educating active, rigorous and flexible individuals, rather than skilled workers for pre-established jobs,

ii) counterbalancing the increasing inequalities and their consequences in terms of poverty and marginalization,

October $22-25,2008$, Saratoga Springs, NY
Formatted: Font: $12 \mathrm{pt}$

$38^{\text {th }}$ ASEE/IEEE Frontiers in Education Conference

T1A-1 
iii) treating diversity as a valuable resource different from inequality,

iv) educating to recreate politics,

v) preparing to face an increasingly broad spectrum of personal decisions, and

vi) preparing for both the introduction and prevention of the paradoxical effects of technical progress.

Braslavsky's observations roughly correspond to the following interests and perspectives which in our view have to be embraced in any kind of future oriented higher education:

\begin{tabular}{|l|l|}
\hline Societal interests: & Education to citizenship \\
\hline Occupational interests: & Education as investment \\
\hline Academic socialization: & Education to membership \\
\hdashline $\begin{array}{l}\text { Education as identity work: } \\
\text { Globalisation of the labour } \\
\text { actualisation and self- } \\
\text { development }\end{array}$ \\
\hdashline $\begin{array}{l}\text { Education to cosmopo- } \\
\text { litanism }\end{array}$ \\
\hline
\end{tabular}

(Based on Troelsen, 2000 [3]).

In recent years a number of important and influential bodies have begun to explore whether the accepted method of educating the engineer is in accord with the global challenges that engineers and engineering are confronted with routinely. For example, the US National Academy of Engineering has described the engineer of 2020 and proposed mechanisms to educate that engineer [4] Educational standards bodies such as ABET and corresponding bodies in Europe, including Engineers Ireland, have developed new accreditation guidelines for engineering programmes to ensure that graduates from these programmes have the skills that were traditionally left to industry to develop in their engineering employees.

Coming from a different direction authors such as Williams [5] and Heywood [6] have argued that the engineering profession has lost its identity. And it is further argued that in the long run engineers will have to face up to a long term convergence between technological and liberal arts education. Their prediction is that if engineers do not adopt a hybrid educational model they will be consigned to purely technical work activities. Consequently the engineer would not be ideally suited to provide the type and level of leadership required in our more complex society.

In Europe, implementation of the Bologna Declaration provides an excellent opportunity to examine how some degree of convergence between technological and liberal arts education can be achieved in the context of a two-cycle engineering system of education. The first cycle, of normal duration three years, might not admit much in the way of such a convergence and it might also be problematic in the second-cycle especially if such a degree is not designed to follow on directly from a specific first cycle one. However there is good scope for incorporating appropriate elements of liberal education in an integrated five year programme. But what should these elements be? Reaching any consensus on this will not be straightforward when one considers, for example, the report by the Royal Academy of Engineering (UK) Educating Engineers for the 21st Century, June 2007 which states that 'Universities must continue to teach 'core engineering' and not dilute course content with peripheral subject matter' [7]. The Royal Academy adds that 'there is a limited requirement for training in key business skills, envisaged primarily as commercial awareness - an understanding of how businesses work and the importance of the customer - combined with the basic principles of project management'. This view contrasts sharply with that of IBM which envisages 'services, sciences, management and engineering "bringing together ongoing work in computer science, operations research, industrial engineering, business strategy, management sciences, social and cognitive sciences, and legal sciences to develop the skills required in a services-led economy'. Going a little further, educators such as Gary Downey have developed an ethnographical approach exploring the relationship between knowledge and personhood (engineer). Again, from an educational perspective, consider Harvey Mudd College, California, which 'seeks to educate engineers, scientists, and mathematicians, well versed in all of these areas and in the humanities and the social sciences so that they may assume leadership in their fields with a clear understanding of the impact of their work on society' [8]. The National Academy of Engineering (US) in The Engineer of 2020 sets the goal that in order to 'maintain the nation's economic competitiveness and improve the quality of life for people around the world, engineering educators and curriculum developers must anticipate dramatic changes in engineering practice and adapt their programs accordingly'. In addition to identifying the ideal attributes of the engineer of 2020, the report recommends ways to improve the training of engineers to prepare them for addressing the complex technical, social, and ethical questions raised by emerging technologies. Boeing has, inter alia, identified the Desired Attributes of an Engineer other than technical ones and that includes a basic understanding of the context in which engineering is practiced. Amongst topics addressed are: economics, history, ethics, the environment, as well as customer and societal needs. Some of the skills identified include: good communications, high ethical standards, an ability to think critically and creatively and independently, the ability and self-confidence to be flexible, and an understanding of the importance of teamwork [9]. What is clear overall is that a body of engineers and engineering educators do believe that the educational development of a 'more rounded' engineer needs to be achieved.

But, however convincing the case might be to some, it is an entirely different matter when it comes to winning the argument with academic staff in an engineering faculty (or school) to include some element of liberal arts education in what is usually an already tightly packed curriculum. And even if an acceptance is won there still remains the problem of deciding how to deliver to the students the chosen liberal arts. For the first challenge there is no ready simple 
solution. Colleges are often conservative for good reasons and are not overly susceptible to the current demands of industry and would generally claim that they are educating their students not for 'the first job' but for life. Nevertheless this 'for life' aspect coupled with the recruitment policies of some influential employers should eventually bring about the conditions by which the engineering curriculum is opened to include liberal arts studies such as philosophy. There is also peer pressure as an agent of change by which well regarded institutions can influence others. Further, once some empirical evidence is accumulated that demonstrates that there are benefits to be obtained, accrediting bodies will be encouraged to make provision in their requirements for a broadened engineering curriculum. Finally, on this first challenge, the identification of some metrics by which the benefits can be assessed in time is a task that engineering educationalists should address now.

In the following we present some of the results of an empirical case study carried out at AU-IBT in Denmark [10] expanding on a survey that had previously been undertaken in DIT, Ireland. The purpose of the Danish case study was to examine a sample of engineering teachers' attitudes towards the relevance and scope of philosophy of science courses for engineering students (a parallel to the US debate on introducing liberal studies in engineering curricula). The data was collected in an anonymous survey. A questionnaire was distributed to 35 potential respondents comprising fulltime teaching staff of three BSc engineering degree programmes in electronics, business development and global management and manufacturing. In all 26 respondents filled in the questionnaire. The set of data collected in the questionnaire survey is obviously too small and too particular to be of any great statistical significance. However we were not aiming at statistical significance and generalization. We were aiming to construct a case study which, despite its limitations, can provide insight into how respondents view the importance, relevance, scope and problems of including philosophy of science into engineering curricula. Our case study can thus serve as an exemplar which we cannot claim on the one hand to be typical but which, on the other hand, we have no reason to believe is atypical of what can be found elsewhere. There is reason to believe that the data gives a valuable insight into real complexities and challenges in introducing philosophy of science courses in engineering curricula

\section{THE MAJOR RESULTS OF THE CASE STUDY}

In the following we present a brief analysis of some core questions from the Danish survey.

Question I 'Please indicate on a scale from 1 to 5 the relevance of the below mentioned issues for philosophy of science courses in engineering studies'

A. Engineering roles and identity

B. Engineering culture and norms

978-1-4244-1970-8/08/\$25.00 @2008 IEEE
Session

C. The design process as a technical and social process

D. Knowledge generation and forms of knowledge in engineering work

E. The importance of technology and its impact on society

F. Ethical problems in engineering

G. Requirements of interdisciplinary and inter-cultural collaboration

\begin{tabular}{|l|l|l|l|l|l|l|l|}
\hline Dimension & A & B & C & D & E & F & G \\
\hline 1. Irrelevant & 2 & 2 & 0 & 0 & 0 & 2 & 0 \\
\hline $\begin{array}{l}\text { 2. Minor } \\
\text { relevance }\end{array}$ & 4 & 7 & 2 & 2 & 0 & 1 & 1 \\
\hline $\begin{array}{l}\text { Subtotal } \boldsymbol{X} \\
\text { 1+2 } \\
\text { Opponents }\end{array}$ & $\mathbf{6}$ & $\mathbf{9}$ & $\mathbf{2}$ & $\mathbf{2}$ & $\mathbf{0}$ & $\mathbf{3}$ & $\mathbf{1}$ \\
\hline $\begin{array}{l}\text { 3. Some } \\
\text { relevance }\end{array}$ & 9 & 7 & 8 & 9 & 4 & 6 & 9 \\
\hline 4. Relevant & 7 & 8 & 10 & 8 & 12 & 12 & 6 \\
\hline $\begin{array}{l}\text { 5. Very } \\
\text { relevant }\end{array}$ & 3 & 1 & 5 & 6 & 9 & 4 & 9 \\
\hline $\begin{array}{l}\text { Subtotal } \boldsymbol{Y} \\
\text { 3+4+5 } \\
\text { Proponents }\end{array}$ & $\mathbf{1 9}$ & $\mathbf{1 6}$ & $\mathbf{2 3}$ & $\mathbf{2 3}$ & $\mathbf{2 5}$ & $\mathbf{2 2}$ & $\mathbf{2 4}$ \\
\hline Total & 25 & $\mathbf{2 5}$ & $\mathbf{2 5}$ & 25 & 25 & 25 & 25 \\
\hline
\end{tabular}

In this question we have combined 4 issues in order to separately measure respondents' attitudes to each of these four issues.

1) a Socratic element of professional self-reflection, dimension A-B-G

2) core areas of philosophy of engineering, dimension C-D,

3) a core area of philosophy of technology, dimension $\mathrm{E}$

4) engineering ethics, dimension $F$

1) In the "Socratic" dimension A-B-G the overwhelming majority of answers (78\%) are proponents of the relevance of a Socratic element of professional selfreflection in engineering studies. However one third of the answers only find that it has 'some relevance'. Also, 16 out of $75(21 \%)$ of the answers even state that it is either irrelevant or of minor relevance. Hence the Socratic 'know thyself' or professional self-reflection is apparently not that self-evident for all staff that participated in the survey. Further if we compare A-B with $\mathrm{G}$ it becomes clear that not all the respondents see these issues as linked together. In fact 24 out of 25 of the respondents are thus proponents of knowledge of interdisciplinary and intercultural collaboration but only 19 are proponents of knowledge of engineering roles and identity and only 16 are proponents of knowledge of engineering culture and norms. However, to us A, B and G are closely related and it is hard to have one without the other. These observations raise a number of important didactic questions for reflection in engineering

October 22 - 25, 2008, Saratoga Springs, NY

$38^{\text {th }}$ ASEE/IEEE Frontiers in Education Conference

T1A-3 
teaching communities such as: Can engineers in a global economy cooperate successfully with people from other professional and national cultures without having been equipped during their studies with knowledge of their own professional role and identity? Or does this knowledge in fact already exist in engineering degree curricula but without being clearly labeled (tacit knowledge)? And is it necessary for engineers to be able to transcend the engineering culture or to know how it looks from the outside?

2) In the core areas of philosophy of science for engineering, dimension C-D, $92 \%$ of the answers find the core areas of philosophy of engineering relevant. And 34\% of these find that these core areas only have some relevance. Only $8 \%$ find that the core areas of philosophy of engineering have minor relevance.

3) As to the core area of philosophy of technology dimension D - the importance of technology and its impact on society - all 25 respondents answer that it is relevant. And only 4 out of 25 (or 16\%) find that it has only some relevance.

4) As to dimension $\mathrm{F}$ - engineering ethics - 22 out of 25 $(88 \%)$ respondents are proponents of the relevance of engineering ethics in philosophy of science courses for engineering studies. Although this is a very high number, given the high degree of focus on ethical issues relating to science and technology in Denmark and other Western countries it is perhaps a bit surprising that 2 respondents find that engineering ethics is downright irrelevant and 1 respondent found that it is only of minor relevance!

If we sum up the analysis of our data from Question I we may say that the overwhelming majority of respondents in fact express a positive attitude to the combination of topics we have suggested for philosophy of science courses in engineering studies. On the face of it, this positive attitude should make it relatively easy to introduce such courses in the engineering degree programmes the respondents are responsible for currently. However, at the time the survey was carried out (spring 2007) the philosophy of science courses had not yet been introduced in the degree programmes in practice but were still on the 'drawing board'. The Danish government recommended the inclusion of philosophy of science courses in degree programmes at the bachelor's level in 2004, Another observation worth highlighting relates to the respondents' attitudes to the Socratic element of professional self-reflection. Here, 24 out of 25 respondents say that knowledge of interdisciplinary and intercultural collaboration is relevant but only 19 and 16 respondents respectively see this kind of collaboration as closely linked to dimension $\mathrm{A}$ - engineering roles and identity and dimension $\mathrm{B}$ - engineering culture and norms.

Question II. 'How would you evaluate the relative importance of research methodology and philosophy of science respectively?'

978-1-4244-1970-8/08/\$25.00 @2008 IEEE
Session

The purpose of this question is twofold: First, as there is a close relationship between research methodology and philosophy of science in traditional scientific disciplines, question 12 measures the relative importance that the respondents attribute to each of these issues. This is an indication of a potential place of philosophy of science courses and the weight the respondents would attribute to the two issues if they were to be combined in a single course. Second, the question also measures the degree to which the perception of engineering as applied science is sustained among engineering teachers and in engineering discourse.

\begin{tabular}{|l|c|}
\hline \multicolumn{1}{|c|}{ Scale } & Frequency \\
\hline $\begin{array}{l}\text { 1.To learn research } \\
\text { methodology is more } \\
\text { important than philosophy of } \\
\text { science. }\end{array}$ & 17 \\
\hline $\begin{array}{l}\text { 2. To learn philosophy of } \\
\text { science is more important } \\
\text { than research methodology. }\end{array}$ & 0 \\
\hline $\begin{array}{l}\text { 3. Research methodology and } \\
\text { philosophy of science are } \\
\text { equally important. }\end{array}$ & 7 \\
\hline $\begin{array}{l}\text { 4. Neither research } \\
\text { methodology nor philosophy } \\
\text { of science is important. }\end{array}$ & 1 \\
\hline Total & 25 \\
\hline
\end{tabular}

Given the instrumental nature of engineering we believe it was to be expected that a clear majority of 17 out of 25 respondents consider the more readily applicable research methodology the main issue rather than the less concrete concepts related to philosophy of science. For us the distribution of answers to this question is also a clear indication that the assertion that engineering is applied science is still sustained among the majority of the respondents. If we thus compare the response frequency of question II with the response frequency of question I C-D this interpretation is put into a wider perspective. The decomposition of the answers in question I C-D shows that only a little more than half the respondents $29 / 50$ or $58 \%$ consider engineering design the core of engineering whereas $21 / 50$ or $42 \%$ only attach "some relevance" or even "minor relevance" to this issue.

Question III. 'In your opinion, how broad and deep should the learning objective of philosophy of science courses be defined?'

In question III we measured the respondents' attitudes as to the desired breadth and depth of philosophy of science courses in engineering curricula. Four answer categories were given ranging from giving philosophy of science no place at all to giving it a very central place in engineering curricula. It was found that 9 of the respondents had very modest ambitions and 2 respondents were even in direct opposition to the introduction of such courses. But 10

October 22 - 25, 2008, Saratoga Springs, NY
Deleted:

Deleted:

$38^{\text {th }}$ ASEE/IEEE Frontiers in Education Conference

T1A-4 
respondents expressed a higher level of ambition and 6 of these a very high ambition arguing that Philosophical reflections should penetrate all courses and activities in engineering studies. Roughly speaking, the group of respondents are thus evenly divided as to the role they see for philosophy of science in engineering curricula.

Question IV. 'As to the teaching aim of philosophy of science courses which of the two options would you prefer?'

This question aims to differentiate clearly between those who see value in considering philosophy of science regardless of the engineering context and those who see a role for the subject in how engineers think about and carry out their work. Note: bildung roughly translates as formation or development.

Question IV

a. Philosophy of science should be a course aiming at Bildung as an end in itself.

b. Philosophy of science should be instrumentalized as a tool for courses in research methodology.

For this question 10 respondents were in favour of Bildung as the ultimate aim of philosophy of science courses whereas 15 preferred courses which are instrumentalized as a tool for courses in research methodology. That the majority is in favour of the instrumental approach is to be expected. We had in fact expected the majority to be even larger - bearing in mind the inherently instrumental nature of engineering. Instead of taking attention away from traditional focus areas of education, philosophy of science courses may in fact be used to strengthen 'engineering proper' through underpinning a time-honoured part of engineering education, i.e. methodology training,. This may be seen as a relief for respondents who may otherwise have felt uncomfortable about engaging in philosophical issues. Answer category $b$ in question IV thus provides an opportunity for respondents to place philosophy of science at what has traditionally been seen as the centre rather than the periphery of engineering education.

Summing up, we may conclude that the majority of respondents in our survey wish to see philosophy of science courses instrumentalized as a tool for project work and courses in research methodology. Furthermore their level of ambition as to the learning outcome can be characterized as middle-range: engineering students in their third year of study should be able to independently use the key concepts and central theories. That the undergraduate student should also be able to critically and independently reflect and theorize on the key concepts and central theories of the discipline is only perceived as a desired goal by a small minority. This would also in our opinion be a somewhat over-ambitious and unrealistic goal.

\section{IMPLEMENTATION - INTRODUCING MATERIAL INTO THE CURRICULUM}

978-1-4244-1970-8/08/\$25.00 @2008 IEEE
When it comes to implementation in the sense of including philosophical and historical material in the curriculum there again is a broad agreement between those surveyed in Ireland and Denmark. In the Danish survey $75 \%$ of the staff were in favour of including such material [10]. In the Dublin case senior staff participating in a relatively similar survey were also generally favourably disposed to including the philosophical and historical material in an engineering programme [11] [12]. But this is in principle! The real challenges are 'who should teach', 'how' and 'how much'.

The first part of the challenge is the trade-off between qualifications and teaching legitimacy as perceived by both students and engineering staff. Given the path dependency of engineering teachers they are likely to have the legitimacy among students but are most likely to lack the qualifications. Academics trained in philosophy of science on the other hand may have the formal qualifications but are likely to lack legitimacy amongst students and to lack the ability to put theories into a relevant, practical engineering context

Regarding the second part of the challenge - how to deliver the liberal arts material in an engineering programme - this question has a parallel with what is sometimes a contentious matter in an engineering faculty, namely should mathematics be taught by engineers to engineers or should mathematics be a subject taught only by mathematicians. Happily the evidence is that both approaches can work and depends heavily on the teaching style, interests and enthusiasm of the staff involved. In the context of a five year masters engineering programme what is being proposed at DIT, initially, is a judicious mix of approaches - judicious, as it is necessary to trial different approaches and evaluate their impact and value before reaching firm conclusions as to how to introduce the material into the curriculum. The overall approach that has been discussed consists of three strands and can be summarized as follows: (a) in the early years of the programme, year two most likely, provide a course (module) that presents an introduction to philosophy of engineering coupled with an overview of the history of engineering, science and technology; (b) from the second year onwards embed in technical subjects material that has a clear philosophical dimension; (c) as part of a design spine and within the last two years of the programme provide a module tailored for a specific discipline that presents a holistic view of a limited number of major engineering projects. Holistic in the sense that the treatment is not purely technical but includes the context and impact on society and the influence, if any, on later developments that derive from the original engineering project. As an aside this last aspect can and generally does demonstrate the process of evolution in engineering design.

\section{CONCLUSION}

It is recognized that eminent authors have addressed most or indeed all of the points raised in this article [13], [14], [15]. But the fact remains that the influence on engineering curricula has been limited. The purpose of the article should be clear - first, to state in the simplest terms possible the

October 22 - 25, 2008, Saratoga Springs, NY

$38^{\text {th }}$ ASEE/IEEE Frontiers in Education Conference

T1A-5 
rationale for the inclusion of both a historical and philosophical treatment of engineering, and second, to set out a minimal scheme to achieve the goal of introducing such material, and third, to act as a working paper as part of a discourse amongst engineering staff responsible for educating engineers.

For some it is sufficient to study these areas for no other reason than that they are interesting topics in their own right, but most engineers would be appreciative if the knowledge, insight and skills so gained allowed them to be better citizens of their profession.

The Danish case study has highlighted an apparent paradox: on the one hand a relatively positive attitude among AU-IBT faculty, which, experience shows, we believe is also found at DIT, as to the relevance of liberal education/philosophy of science in engineering curricula and on the other hand lacking concrete actions of implementation amongst the very same faculty - in both Denmark and Ireland. However given the path dependency of engineering as a knowledge domain outlined above the difficulties of implementation is perhaps not so surprising. The biggest surprise is therefore the generally positive attitude among the respondents. This could of course be written off as a simple consequence of the fact that the very establishment of an institutional discourse on philosophy of science in the engineering degree programmes through putting it on the agenda at both DIT and AU-IBT has made respondents more positive to philosophy of science. It is a well-known fact that there may be differences between people's attitudes ex ante and ex post of gaining knowledge of a phenomenon. However, we believe that this cannot explain in full the rather surprising positive attitudes found in the Danish survey which is also due to the fact that we were very conscious of formulating the questionnaire in a neutral way. We thus believe that the positive attitudes are also an indication of a more general phenomenon, i.e. that although contemporary culture of engineering is still to a large extent rooted in a de-contextualised, relatively narrow technical/applied science approach, there is also an openness towards discussion of broader issues amongst our respondents. We were surprised to see that in the Danish survey $40 \%$ were in fact in favour of Bildung as the ultimate aim of philosophy of science courses. It thus seems that the general attitude amongst faculty in the survey is that philosophy of science may help improve studies. How to go from attitude to action is, however, the major challenge. As our case study shows, it has to be recognized by education managers, teachers and students that given the history and culture of engineering it takes time to successfully implement philosophy of science courses in engineering degree programmes: 'the spirit indeed is willing, but the flesh is weak'.

\section{REFERENCES}

[1] Golden, Jack. [please insert more precise reference]
[2] Braslavsky, COBSE Conference 2002 [please insert more precise reference]

[3] Troelsen, R. R. 2000. Kompetenceudvikling i kemiuddannelserne. In, B $\emptyset$ rsen Hansen, Tom et al. Naturvidenskab, dannelse og kompetence. Aalborg University Press.

[4] US Academy of Engineering. The engineer of 2020. [please insert more precise reference]

[5] Williams, Rosalind. [please insert more precise reference]

[6] Heywood, John [please insert more precise reference]

[7] The Royal Academy of Engineering, Educating Engineers for the $21^{\text {st }}$ Century, http://www.raeng.org.uk/education/ee21 c/default.htm: 2007

[8] Harvey Mudd College [please insert more precise reference]

[9] Boeing. [please insert more precise reference]

[10] Christensen, Steen Hyldgaard \& Ernø-Kjølhede, Erik, Philosophy of Science in Engineering degree programmes. Trojan Horse or necessary curriculum improvement? Forthcoming

[11] Grimson W., Engineering - An Inherently Philosophical Enterprise, Academica, Aarhus (2007). In Cristensen, S. H., Meganck, M. and Delahousse, B. (eds). Philosophy in Engineering, pp 89-102.

[12] Grimson W. The Philosophical Nature of Engineering - a characterization of Engineering using the language and activities of Philosophy. ASEE Conference Proceedings (2007)

[13] Durbin P (ed), Critical Perspectives on Nonacademic Science and Engineering, Lehigh University Press.

[14] Bucciarelli L, Engineering Philosophy, IOS Press (2003).

[15] Mitcham C., The Importance of Philosophy to Engineering. Technos Vol. XVII/3 1998 / http://campus- oei.org/salactsi/teorema02.htm

\section{AUTHOR INFORMATION}

Erik Ernø-Kjølhede. Director of the Institute of Business and Technology, University of Aarhus, Herning, Denmark.

Mike Murphy. Director of Dublin Institute of Technology and Dean of the Faculty of Engineering. He is also chair of the Academic Society of Engineers Ireland.

Steen Hyldgaard Christensen. Senior Lecturer, Institute of Business and Technology, University of Aarhus, Herning, Denmark. Initiator and coordinator of a current EuropeanAmerican research project entitled "Engineering in Context".

William Grimson Currently Head of Student Registration Records with special responsibility for coordinating the introduction of a modularized system of programmes in the Dublin Institute of Technology, Ireland. 